\title{
On the moors with Ted Hughes and Ovid
}

\section{Mike Stephenson recounts a recent geology walk which revealed links between poetry and geology}

1 ou could say that geology is the study of transformation - how physics, chemistry and biology wreak their changes on the earth. Earth's rocks contain records of those transformations; an entire class of rocks ('metamorphic') is named after change of form. Observing the characteristics of change helps geologists reconstruct the processes that cause it, and recognise the states of change along the way. We even use a term co-opted from literature - 'palimpsest' - that describes structures in rocks that give clues to their ancient origin where the superimposed changes have not removed everything.

A recent walk on the moors with the Yorkshire Geological Society to celebrate the geology and poetry of Ted Hughes made me think of the similar ways that geologists and poets explain and react to the landscape and processes of change around them.

\section{Metamorphosis}

The walk started at Widdop Reservoir above Hebden Bridge and scaled the moors over wild Cludders Rocks down to Dicken Rocks. I read some of the best poems from Hughes' collection The Remains of Elmet, and also introduced the group to Hughes' translation of Ovid's Metamorphoses. Reading Ovid's tale of Niobe, a woman so struck by grief that she turned to stone, while standing underneath the overhanging human-like masses of Dicken Rocks seemed to bring the 2000

year-old poetry to life. I was struck by how transformation is central to the work of both the poets and geologists.

Three of Hughes' poems, Wild Rock, Hillstone Was Content and Moors, were popular with the Yorkshire Geological Society walkers perhaps because they too explored the idea of change. The first two were inspired by pictures by the photographer Fay Godwin of Cludders Rocks and scenes of stone buildings on Calder valley hillsides. Cludders Rocks is a scarp of lower Kinderscout Grit above a tumble of boulders overlooking Widdop reservoir. The two poems explore a theme of Hughes' - that of stone taken from its natural hill habitat, and cut and fashioned for building. He speaks of the stone being 'conscripted' for the building of houses and mills in the industrial revolution, while the people of the valleys dream of industry, or organised work:

converting their ideas to woollen weave

In Hill-stone Was Content Hughes is fascinated by the transformation of stone from the stuff of the hillsides, the load-bearing layers of the landscape, to a captured and controlled existence in the walls of factories and houses. He sees this cut stone itself undergoing change - being worn down by the persistent rain, but trying to resist:

Against the guerrilla patience Of the soft hill water

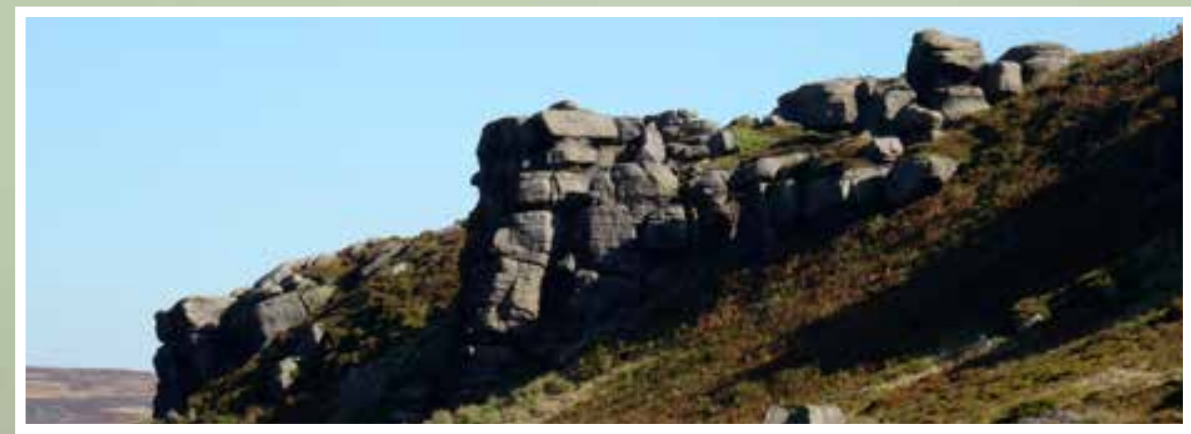

Cludders Rocks, made up of the lower Kinderscout Grit, once cut and carted to build the houses, factories and mills of the industrial revolution of the Calder Valley

\section{Topheavy Kings and Queens} It was at nearby Dicken Rocks, over the hill from Cludders Rocks, where Hughes' translation of Ovid's ancient verse and his own poem Moors seemed to speak to the group most vividly. Where Cludders Rocks are a disorganised tumble, Dicken Rocks are more orderly - a roughly continuous vertical face of coarse sandstone cut by joints that divide the face into vertical masses, each perhaps seven meters high and a metre or so wide.

These masses crowd together shoulder to shoulder and most strangely overhang slightly, perhaps because of a harder upper layer. They are striped with cross bedding and in several of the upright blocks this appears to cover a lower, darker overhanging part to give the impression of draped or cloaked faces. The internal structure of the sandstone reinforces the impression of human-like shapes. Even the arc of the cliff turned toward you seems to suggest that the figures are advancing:

A chess-world of topheavy Kings and Queens

Circling in stilted majesty.

Tremble the bog cotton

Under the sweep of their robes

At Dicken Rocks, I read Hughes' translation of Niobe - of the transformation of the woman, the mother, to stone:

Her tongue

Solidified in her stone mouth. Her feet could not move, her hands Could not move: they were stone

Here the transformation of the living woman to stone leaves recognisable human features of 'stone packed in stone'. The image is all the more arresting because the vestiges of the previous state before transformation can be seen, like a palimpsest. At Dicken Rocks 
you are confronted by rock masses that are so uncannily human that Ovid's poem seems to have greater effect, capturing the imagination.

Of course, geologists tend to see the rock and its origin from the point of view of modern science; the features of the ancient environment of deposition, for example. The seemingly 'hooded faces' are erosions of cross-bedded sandstone. We know that this structure formed by deposition on the inclined surfaces of ripples and dunes, indicating a flowing medium - in this case water in the 315 million-year-old 'Kinderscout Grit delta'. We also know that this delta spread from the north and was a river feature the size of the biggest modern deltas. But that's where the comparison ends - this Carboniferous delta would have been unfamiliar to the modern eye, the land around it obviously devoid of animal and human life but also devoid of modern typical plant life, like angiosperm plants.

Perhaps to a Roman reader of Ovid, two thousand years ago, the geological explanation of the origin of the stones of Dicken Rocks might have been harder to accept than an ancient human-to-stone transformation. Which explanation sounds stranger - a river delta in a weird unearthly landscape turned to stone, or people turned to stone?

\section{Stage for the performance of heaven}

The Remains of Elmet is filled with descriptions and images that recall human and animal shapes, and the presences of gods and supernatural forces. In the poem Moors Hughes says that these high plateaux

Are a stage for the performance of heaven Any audience is incidental

On his walks as a boy on the moors above Hebden Bridge, Hughes saw the actors on this stage all around him - the misshapen rocks, the stunted moor trees, the freezing glassy lakes. He imagined dramatic events under the wild sky: titanic struggles and capitulations, murders and kidnappings. This personal mythology, his strange imagination, was informed by ideas from geology and geomorphology, transformed by his interest in non-European cultures and in the 'otherness' of animals.

I read the last of the poems, Moors, to the group as we looked west toward Lancashire at the barren upland of Hare Stones Hill and Black Clough. Reading it aloud in the place where the poem was probably inspired gave the verse a peculiar power. It seemed at least to me for a moment that the moors could be a kind of wild stage and that the rubbly stones that roughened the horizon could be gatherings of ancient, supernatural kings or gods. The audience may have known that the slopes were sculpted by Pleistocene glaciers rather than monsters, and that the upstanding rocks owed their shapes more to joints caused by pressure release than to human transformation. But perhaps for the group, just for a brief instant, it was possible to believe in the transformations of Ovid and Ted

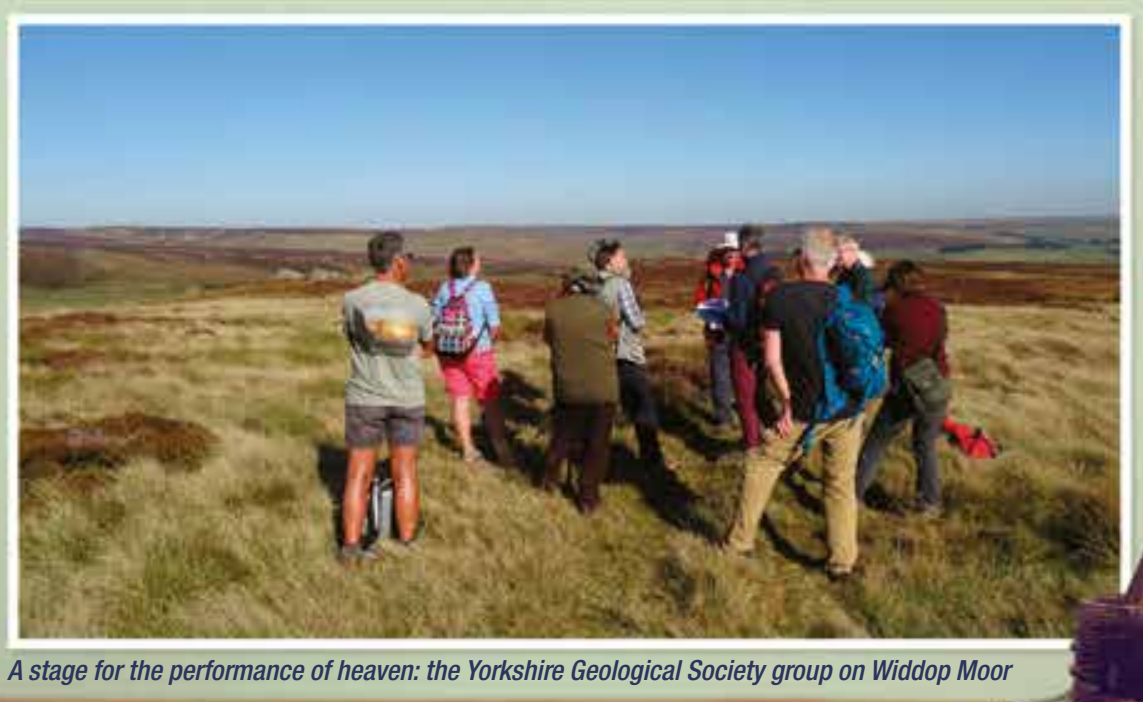

Hughes, and to imagine the landscape through eyes less conditioned by modern science.

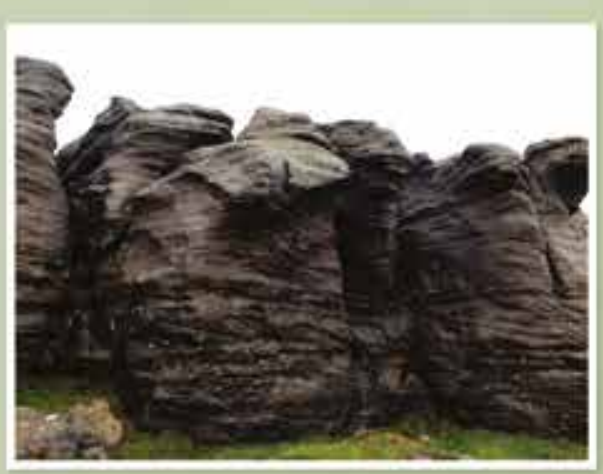

Dickens Rocks: topheavy Kings and Queens

.

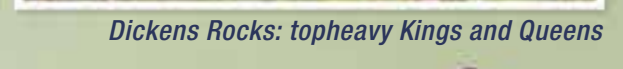

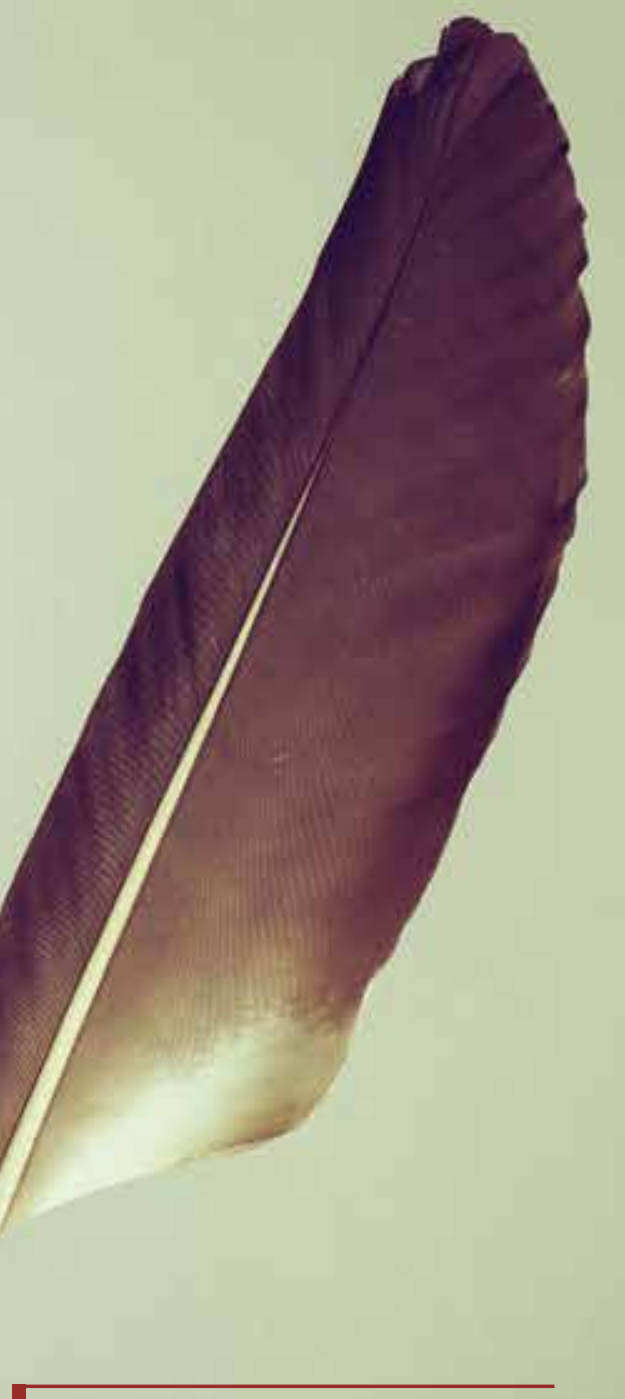

Prof Mike Stephenson is Executive Chief Scientist at the British Geological Survey.

Email: mhste@bgs.ac.uk. 